\title{
Neuroimages: Some Serving Suggestions
}

\author{
Benedict Charles Taylor-Green (D)
}

Received: 14 July 2021 / Accepted: 15 July 2021 / Published online: 6 August 2021

(C) The Author(s) 2021

\begin{abstract}
This art-science interaction evokes two 'neuroimages'. However, the term 'neuroimage' does not refer, as usual, to images that emerge from scientific practices that seek to gain insight into the structural and functional properties of brains. Rather, it is meant that the images considered have as their theme neurotechnologies: specifically, those that concern the control of neuroprostheses, and neuroprostheses themselves. The first neuroimage appears in a biosignal sensing cap catalogue, and the second appears in the science fiction film Blade Runner 2049. While neither neuroimage is actually included in the piece, each is described to the reader before being speculatively analysed, and therefore becomes a 'mental' image in the mind's eye, calling upon the ancient art of ekphrasis.
\end{abstract}

Keyword Brain-computer interface .

Neuroprosthetic · Drone swarm - Science fiction ·

Ekphrasis · Anthropology

\section{Tales from the Catalogue}

1: A man, Caucasian, medium build, late twenties, sits confidently in a mid-range car, wearing a carefully distressed leather jacket and blue jeans. One arm

B. C. Taylor-Green $(\bowtie)$

School of Anthropology and Museum Ethnography,

University of Oxford, Oxford, UK

e-mail: benedict.taylor-green@anthro.ox.ac.uk outstretched, hand on the steering wheel, the other, it seems, reaching down to the gear stick out of shot. We see him almost side on, left side occluded from view, staring out of a section of the windscreen to which only his gaze is privy. Out of the front-side window, directly in the observer's line of sight, central to the image, we can see some buildings, suggesting a wider urban spread. Brief flickers in the amodal depths of the autonomic virtual body begin to evoke a broader space $[1,2]$, but we don't get enough information to say what we might be looking at. In theory, despite certainly indexing $a$ place, some buildings, the photograph could have been taken in any number of locations on Earth. The viewer observes a 'non-place' [3] through the window in the centre of the image.

Notably, the man is wearing a wireless biosignal sensing cap, capable of recording, by means of electroencephalography (EEG), variations in electrical potential in brain tissue as 'chains of ions leap from one neuron to another in an electrical current' [4 $\mathrm{p}$. 143], corresponding to, for instance, motor intention or sensory stimulation. This high-end cap can also utilize functional near-infra-red spectroscopy (fNIRS) to monitor haemoglobic fluctuations in the blood moving through cortical regions. In fact, EEG and fNIRS can be combined in several ways to improve the classification accuracy of cerebral recordings, and subsequently the control of a neuroprosthetic [5]. We cannot tell in this instance whether it is EEG or fNIRS at work, and more importantly, neither can we tell whether the cap is simply monitoring the man's biosignals or facilitating their use in a brain-computer interface (BCI) control paradigm. 
Staring out of the window is often a creative act: 'it's not always easy to spot when someone is idle or daydreaming' [6 p. 69]. Indeed, as Steinert et al. [7] see it, this is the primary peculiarity of BCI-mediated actions. Even if the man were acting, and by this, now, we mean technologically mediated physical action caused by mental actions that do not involve organic bodily movements, potentially at a remote location: we may not be able to tell simply by observing him.

2: Captioning this image, the vendors claim due to its superior quality, their 'research' model can obtain excellent electroencephalographic recordings in less than ideal, non-laboratory conditions, for example, vehicular oriented neuro-research and/or control applications from the terrestrial to the extra-terrestrial. Let's pretend we are dealing with a vehicular EEGbased BCI control paradigm, in which, reductively, 'the brain can be viewed as an electrical signal generator' [8, p. 122].

3: An image, presumably commissioned by the company, functioning as a specifier of product usage, made as a marketing tool, positing vehicular futures. Yet, in this image, and the others in the catalogue - like picture-perfect strawberries, depicted on but never actually present in cereal boxes, glistening with droplets of pre-picking dew, caught in the act of tumbling into a bowl amidst bran-based flakes splashed with milk: the intended narratives, internal to the image [9] expressed by the arrangements of bodies and things resembling the possibilities of application, are mere serving suggestions, which like those cereal box strawberries, may in the end have little relation to the cereal we end up eating. There is a rift between the serving suggestions and what will eventually be actual uses, which, given the nature of the device as connector, are impossible to exhaustively imagine, let alone definitively control.

Thus, at the same time, this image embodies a struggle with a sublime biotechnological excess [10] due to its artefactual content. A device whose technical essence is found in its potentially infinite connectivity and thus endless recombination, involving always, on one end, the human cranium, linked to a mediating computer — but after that... it's anyone's guess. Biosignal sensing caps in their relation to BCI prosthetics evoke the mathematical sublime as prefigured in Jorge Luis Borges' Library of Babel, or in the figure of the biotechnological database such as the one in which the sequenced human genome is stored, in terms of 'the combinatorial explosion' contained in the 'possibility of a finite number of elements' [10 p. 36] which approaches the infinite. What is at stake is the ability to be simultaneously present, in near-real time (at least to an extent) in any number and kind of bodies existing at diverse proximities from the organic locus [11 cf. 12]. BCI, and its possibilities for connectivity and remote agency through the prosthetic, has something of the 'practical dimension of the mathematical sublime' [10 p. 37]. The artefact seethes into synecdoche with the being of the image that carries it, and its escape from final meaning. Backgrounded by the story the image makers want it to tell [9] are the affordances of such biosignal acquisition caps. The potential connectivity of the cap appears subdued by the specificity of the instrumental imaginary [13].

4: The original catalogue I came across from this company in 2018 was less polished, and much funnier. Immediately, one notices the inane, verging on narcotically induced facial expressions of the models: ridiculous smiles, glassy eyes, and hints of a fight with laughter, held off for the instant of the image making. One young woman is riding a microscooter; another looks alluringly over her shoulder at the camera; another with a glistening white smile offers her headshot into the mix. A grey-bearded man stares off into the distance contemplatively. They are all wearing versions of the wireless biosignal sensing cap. It's almost as though there's an inside joke. This is a very silly hat.

Alas, much of, but certainly not all of this playful irony is lost in the sleeker, more recent catalogue, the aesthetic of which is exemplified by this image of the man in the vehicle - not smiling, but not frowning - conveying a sterile quiet. An image of the commercially available post-laboratory biosignal sensing cap: just what you need for facilitating a tepid mastery of mind over matter.

\section{Niander's Swarm}

1: The focus of this second cinematic neuroimage is a neuroprosthetic incorporated by the fictional character Niander Wallace in the 2017 film Blade Runner 2049 [14]. In the film narrative, Wallace 
took over Tyrell Corporation and redesigned their synthetic replicants (who, as depicted in Blade Runner [15], were in some cases all too human) - to obey, feel less, and be better slaves: 'that is how I took us to nine new worlds...nine... a child can count to nine on fingers. We should own the stars!' In his drive to colonize more and more of the galaxy using replicant slave labour, he has realized the limitations of his manufacturing power. He wants to breed replicants in order to supplement the deficit between his vision and reality. Tyrell Corporation succeeded before him in creating a replicant capable of reproducing, biologically, knowledge, which if he possessed it could supplement, even surpass, the workforce in its present quantity. He thus knows it to be possible, but frustratingly his own efforts regarding procreation have failed.

In the film, Wallace Corporation HQ is an echoing brutalist cathedral of soaring angular spaces enveloped in shadows, scintillated by reflections of soft yellow-orangey light that passes through, and utilizes reflections from gently lapping pools of water. Found sitting in an area of almost total darkness, Wallace moves into the light, eyes clouded and silvery. He is blind. Hair slicked back, dressed in a black kimono, he inspects a female replicant from the latest run. Luv, 'best angel of all', is standing by in awe of her creator as he monologues, lording his palpations over the newly emerged and utterly supine replicant's body...naked, shivering, covered in viscous pale yellow gel... a techno-amniotic fluid: 'The first thought tends to fear, to preserve the clay, it's fascinating...before we even know what we are...we fear to lose it. Happy Birthday...shhh.'

Wiping his hands methodically with a white towel, Wallace signals that he is done with touch: 'Now let's have a look at you', he utters more to himself than to the replicant at his feet. Luv steps up beside Wallace producing a slide-top prismatic wooden box filled with a tightly arranged line of seven small oblong devices. She carefully picks a white one from the box. The decoupling from the holster produces a soft, almost inaudible click. Luv delicately approaches Wallace with the device between manicured fingernails. A second click with more of a snap to it echoes around the cathedralic space, sounding an instance of magnetic coupling to a transdermal but presumably quite invasive neural implant on the left side of Wallace's neck. A blue LED turns on several inches below the coupling site.

In the doorway, six black teardrop-shaped drones linked wirelessly to Wallace's neural implant — each the size of a smart phone - ominously congregate. A close-up shows a small rounded lens at what appears to be the front of each drone. Self-sufficiently hovering, the drones appear highly aware of their operations alone and as a swarm feeding back to and controlled by Wallace's mind - suggesting a mixture of top-down control by the incorporator and local selforganizing morphodynamic principles at work [16]. Wallace has the drones circle the replicant's body from foot to head. A curious, intelligent, creaking, clicking, purring, almost conversational machinic twittering can be heard. Perhaps the drones restore to Wallace the capacity of ordinary vision via technological mediation, but perhaps also utilize x-ray, ultrasound, and other non-organically accessible spectra, because the blind man is somehow able to look through her skin, into her body, and determine her infertility: 'the dead space between the stars'.

2: Deleuze and Guattari contend that the key to understanding the difference between the weapon and the tool is in a 'differential method that establishes the distinction...from at least five points of view: the direction (sens) (projection-interoception), the vector (speed-gravity) the model (free actionwork) the expression (jewellery-signs), and the passional or desiring tonality (affect-feeling)' [17 p. 469]. However, the characteristics of a given technology are not 'intrinsic' - rather they are 'logical or conceptual' [17 p. 460] and relate to the assemblage within which they emerge, according to the various passional or desiring factors motivating a particular 'organization of work and variable assemblages of human, animal and thing' [17, p. 465]. Broadly speaking - these and other differential 'points of view' - for which, in this sense I prefer the term aspects - might be taken to characterize the 'dynamic space' [17 p. 471] of prostheses in which they express, generate, and transmit affect [cf. 18].

Stylistically, the morpho- 'dynamic space' [17, p. 471] of Niander's swarm is, in terms of formal, surface aesthetic, positional, and proxemic aspects differential from the vast majority of what Steinert et al. [7] in their analysis of BCI-mediated actions and neuroprosthetics 
call 'quasi-bodily devices'. The latter, which even if thought-controlled are generally constrained by the mass of the incorporator's and/or their own bodies. They are usually singular and continuous with or at least in the egocentric space of the organic body of the incorporator. They are often skeuomorphic in relation to it [cf. 19], frequently informed by the material 'semiotic ideology' [20] of restorative medicine. We might see this material semiotic ideology expressed, for instance, in the proxemic, positional, surface aesthetic, formal, and functional mimesis of an organic human limb. Instead, the drones fit into the loose category of 'non-quasi-bodily devices' [7], which in this image are remotely controlled, non-skeuomorphic, multiple, airborne (and multi-sensorial), albeit here retaining both the instantiation of the proxemic aspect through wireless control and presence in egocentric space. The prosthetic here does not mimic the classic humanist style [21], often dependent at once on the presupposition of specific rather than universal lack, and the struggle for wholeness [22]. What appears in and beneath the specifics of this re-sculpting and multiplication is the potentiality of native style [cf. 23].

3: Following Deleuze and Guattari's understanding of key differences between weapons and tools: being comprised of projections and what could well become projectiles, Niander's swarm strays towards the weapon. However, the drones clearly provide interoceptive feedback, so, exploding the differential method, the swarm is also a tool. Although this is hardly a surprise, because, no matter how we try to separate them, the tool and the weapon have always and will always mutate into one another. The differential method is only heuristic: 'Everything is ambiguous' [17 p. 469]. But, to be sure, regardless of the malign character incorporating it, and, indeed, the ominous atmosphere the filmmakers have crafted, there is a viciousness insinuated by the swarm. It is worth considering that in the smallest measurable space between the organic body and remotely controlled neuroprosthetic - particularly when the latter is not limited to linear displacement or constrained by the mass of the incorporator's or its own body lies the real possibility of the prosthetic as sustained projection and projectile, tending towards 'absolute (mental) speed' [17 p. 466] [cf. 24]: quite possibly operating in 'pack modes' [17 p. 279] [cf. 25].

\section{Neuroimaging}

Despite their more or less shared technological theme, the temporalities, materialities, genre, aesthetics, intentions, and content of each neuroimage is very different. On the one hand, we might initially be tempted to say that as a marketing tool, the first is largely instrumental, strategically backgrounding the biotechnological sublime associated with the infinite potential for connectivity in the artefact, while on the other, the science fictional image from Blade Runner 2049 foregrounds the latter precisely for spectacular effect. In one sense, this is true. But in another, deeper sense, it must be recognized that both simplify the potentiality of the BCI as connector by depicting 'serving suggestions'.

Although unquestionably exploiting the potentiality of the BCI as connector in a more radical manner, in the second neuroimage, a careful naturalization of the prosthetic swarm is achieved by the use of a wireless, ambient intelligence paradigm [26, 27], in synergy with a minimalist, future zen sensibility. An appreciation of aesthetic techniques pertaining to the prosthetic body, which tend towards backgrounding in a phenomenological register for incorporator and onlooker alike, is revealed. The nativity of the swarm is not and never could be achieved via humanist mimesis [cf. 28]. The instrumentality of the second, science fictional neuroimage, then, goes beyond mere entertainment and concerns "what it means to be embodied in high-tech worlds' [29 p. 92] [cf. 30, 31].

Open Access This article is licensed under a Creative Commons Attribution 4.0 International License, which permits use, sharing, adaptation, distribution and reproduction in any medium or format, as long as you give appropriate credit to the original author(s) and the source, provide a link to the Creative Commons licence, and indicate if changes were made. The images or other third party material in this article are included in the article's Creative Commons licence, unless indicated otherwise in a credit line to the material. If material is not included in the article's Creative Commons licence and your intended use is not permitted by statutory regulation or exceeds the permitted use, you will need to obtain permission directly from the copyright holder. To view a copy of this licence, visit http://creativecommons.org/licenses/by/4.0/. 


\section{References}

1. MacDougall D (2006) The body in cinema. In: The corporeal image: Film, ethnography, and the senses. Princeton University Press, Princeton, pp 13-31

2. Nanay B (2010) Perception and imagination: Amodal perception as mental imagery. Philos Stud 150(2):239-254

3. Augé M (2008) Non-places, 2nd English-language edn. Verso, London

4. Helmreich S (2013) Potential energy and the body electric: Cardiac waves, brain waves, and the making of quantities into qualities. Curr Anthropol 54(5):S139

5. Khan MJ, Hong K (2017) Hybrid EEG-fNIRS-based eight-command decoding for BCI: Application to quadcopter control. Front Neurorobot 11(6). https://doi.org/10. 3389/fnbot.2017.00006

6. Frederiksen MD (2018) An anthropology of nothing in particular. Zero Books, Croydon

7. Steinert S, Bublitz C, Jox R, Freidrich O (2019) Doing things with thoughts: Brain-computer interfaces and disembodied agency. Philos Technol 32(3):457-482

8. Meriño L, Nayak T, Kolar P, Hall G, Mao Z, Pack DJ, Huang Y (2017) Asynchronous control of unmanned aerial vehicles using a steady-state visual evoked potential-based brain computer interface. Brain Comput Interfaces 4(1):122-135

9. Banks M, Zeitlyn D (2015) Visual methods in social research, 2nd edn. SAGE, London

10. de Mul J (2012) The (bio)technological sublime. Diogenes 59(1-2):32-40

11. de Mul J (2003) Digitally mediated (dis)embodiment. Inf Commun Soc 6(2):247-266

12. Block K (2019) Machina sapiens: Digital posthumanism from the perspective of Plessner's logic of levels. Hum Stud 42(1):83-100

13. Massumi B (2002) The evolutionary alchemy of reason. In: Parables for the virtual: Movement, affect, sensation. Duke University Press, Durham, pp 89-132

14. Blade Runner 2049 (2017) [DVD] Directed by D. Villeneuve, H. Fancher and M. Green. Hungary: Warner Bros

15. Blade Runner (1982) [DVD] Directed by S. Ridley. Los Angeles: Warner Bros

16. Slavkov I, Carillo-Zapata D, Carannza N, Diego X, Jansson F, Kaandorp J, Hauert S, Sharpe J (2018) Morphogenesis in robot swarms. Sci Robot 3(25)

17. Deleuze G, Guattari F, Massumi B (2013) A thousand plateaus: Capitalism and schizophrenia, Bloomsbury Academic, London

18. Ash J (2015) Technology and affect: Towards a theory of inorganically organised objects. Emot Space Soc 14(1):84-90
19. Knappett C (2002) Photographs, skeuomorphs and marionettes: Some thoughts on mind, agency and object. J Mater Cult 7(1):97-117

20. Keane W (2003) Semiotics and the social analysis of material things. Lang Commun 23(3-4):409-425

21. Lingis A (2006) The physiology of art. In: Smith, M \& Morra, J (eds) The prosthetic impulse: From a posthuman present to a biocultural future. MIT Press, Cambridge, pp 73-90

22. Shildrick M (2015) "Why should our bodies end at the skin?": Embodiment, boundaries, and somatechnics. Hypatia: A Journal Of Feminist Philosophy 30(1):13-29

23. Pellizzi F (2003) Anthropology and primitivism. Res: Anthropol Aesthet 44(1):5-9

24. Yan N, Wang C, Tao Y, Li J, Zhang K, Chen T, Yuan Z, Yan X, Wang G (2020) Quadcopter control system using a hybrid BCI based on off-line optimization and enhanced human-machine interaction. IEEE access 8:1160-1172

25. Jeong J, Lee D, Ahn H, Lee S (2020) Towards braincomputer interfaces for drone swarm control. 8th International Winter Conference on Brain-Computer Interface (BCI), pp 1-4. https://doi.org/10.1109/BCI48061. 2020.9061646

26. Verbeek PP (2009) Ambient intelligence and persuasive technology: The blurring boundaries between human and technology. NanoEthics 3(3):231-242

27. Heylen D (2012): Ambient utopia. In: Bosse T (ed) Agents and ambient intelligence: Achievements and challenges in the intersection of agent technology and ambient intelligence. IOS Press (ebook), Washington D.C., pp 3-16

28. Penaloza CI, Nishio S (2018) BMI control of a third arm for multitasking. Sci Robot 3(20):1-6

29. Haraway D (1985) A manifesto for cyborgs: Science, technology and socialist feminism in the 1980s. Socialist Review 80:65-107

30. Gell A (1988) Technology and magic. Anthropol Today 4(2):6-9

31. Grunwald A (2010) From speculative nanoethics to explorative philosophy of nanotechnology. NanoEthics 4(2):91-101

Publisher's Note Springer Nature remains neutral with regard to jurisdictional claims in published maps and institutional affiliations. 